\title{
ECA: An E-commerce Consumer Acceptance Model
}

\author{
Tiziana Guzzo ${ }^{1}$, Fernando Ferri ${ }^{1} \&$ Patrizia Grifoni ${ }^{1}$ \\ ${ }^{1}$ Institute for Research on Population and Social Policies, National Research Council, Italy \\ Correspondence: Patrizia Grifoni, Institute for Research on Population and Social Policies, National Research \\ Council, Italy. E-mail patrizia.grifoni@irpps.cnr.it
}

Received: October 17, 2014

Accepted: November 11, 2014

Online Published: December 25, 2014

doi:10.5539/ibr.v8n1p145

URL: http://dx.doi.org/10.5539/ibr.v8n1p145

\begin{abstract}
The paper starts from the hypothesis that consumers' purchase decisions are strongly influenced by other members of social network and in particular by people with the same interests, social affinity, their centrality in the network and the electronic word of mouth. Starting from an analysis of literature on user acceptance, we developed a model called E-Commerce Consumer Acceptance - ECA that takes into account specific elements that influence consumer acceptance in the context of the online social networks. The paper extends the Technology Acceptance Model - TAM and TAM2 from a social network perspective to analyze how social influence can affect consumer acceptance of e-commerce in the specific context of social networks.
\end{abstract}

Keywords: electronic word of mouth, homophily, network centrality, social influence

\section{Introduction}

In the last years there has been an increase in e-commerce. Consumers are more and more attracted by purchases on the Internet due to its convenience in terms of times and costs. Consumers before make an online purchase ask the opinion of their friends or reference group as the perceived risk is higher than traditional purchases (Ferri et al., 2008). The factor of trust is very important in e-commerce consumer acceptance. In this context social networks are playing a crucial role, they stimulated a further development of marketing (marketing 2.0) defining a new perspective connected to the symmetry of companies and consumers in their communication process. Indeed, consumers do not passively receive marketers' messages; they actively express their needs, preferences and choices, ask opinions of their friends and read online reviews (Guzzo et al., 2012). These tools, in fact, are significantly changing the relationship between consumers and retailers offering new potentialities, not available in traditional channels, and facilitating collaboration and sharing among users. Customers can easily obtain information about products from a large, geographically dispersed population, the resulting electronic word of mouth and its easy access are increasingly important in affecting consumer acceptance. Online social networks changed old models of word of mouth marketing based on one-to-one relationships, providing a model based on one-to-many amplification of key brand messages, information and reviews from customers. When a user shares its reviews, opinions and ideas about products on its own social channels, this information is exponentially spread, and many other users can be influenced in their future purchases. In this perspective, the issue of consumer acceptance is acquiring a great importance in order to address online retailers to adopt the best strategies to attract consumers.

Nielsen data (2012) found that $98 \%$ of consumers trust recommendations from their networks in the form of social word of mouth more than other forms of advertising. The second most trusted form of advertising is online consumer reviews with an increase of $15 \%$ in four years. According to Randall Beard, global head at Nielsen (2012). "Although television advertising will remain a primary way marketers connect with audiences due to its unmatched reach compared to other media, consumers around the world continue to see recommendations from friends and online consumer opinions as by far the most credible. As a result, successful brand advertisers will seek ways to better connect with consumers and leverage their goodwill in the form of consumer feedback and experiences."

There are not many studies on consumer influence in social networks and consequently acceptance of online purchases. TAM2 introduced the concept of social influence by using the construct of subjective norm, which is defined as the perception of a person of what is important to other people (Venkatesh \& Davis, 2000). However, limited attention has been given to the study of how social influence occurs in social networks environments and 
in relation to e-commerce. The paper aims to analyse how social influence act in the context of social networks and which variables to consider in order to provide additional explanations on the consumer acceptance. After a comprehensive review of literature and analysis on the factors that affect the acceptance, we developed a reference model called E-Commerce Consumer Acceptance - ECA, introducing some variables that act in social networks environment and affect acceptance.

The paper is organized as follows: in Section 2, some related works on users' acceptance are provided. Section 3 introduces the method used in the study. In section 4, a discussion on Social Influence and on Network Centrality, Homophily and Electronic Word of Mouth is provided. In section 5, the E-Commerce Consumer Acceptance ECA Model is introduced. Finally, Section 6 concludes the paper.

\section{Background}

Several studies and models have been developed to represent and explain user's technology acceptance such as: the Theory of Reasoned Action (TRA) (Fishbein \& Ajzen, 1975; Ajzen \& Fishbein, 1980); the Theory of Planned Behavior (TPB) (Ajzen, 1985); the Technology Acceptance Model (TAM) (Davis, 1989); the TAM 2 (Venkatesh \& Davis, 2000); the Unified Theory of Acceptance and Use of Technology (UTAUT) (Venkatesh et al., 2003).

According to the Theory of Reasoned Action, social behavior is motivated by an individual's attitude towards executing that behavior. The main factors that determine behavioral intentions are: the person's attitude towards the behavior (which refers to the person's judgment that performing the behavior is good or bad) and subjective norms (which reflect the person's perception of social pressures put on him/her to perform or not that behavior or not). The TRA is related to voluntary behavior. The theory of planned behavior claims that behavior is not always voluntary and under control, it can be deliberative and planned introducing a new component, the "perceived behavioral control." It is related to the extent to which the person believes that $\mathrm{s} / \mathrm{he}$ has control over personal or external factors that may facilitate or limit behavioral performances (Ajzen, 1991). TPB suggests that individual's behavioral intentions and behaviors are shaped together by their attitude towards behavior, subjective norms, and perceived behavioral control. The most famous and applied model is the Technology Acceptance Model. It is derived from the Theory of Reasoned Action of (Ajzen \& Fishbein, 1980); and deals with users' acceptance and use of technology (Davis, 1989).

The TAM considers different connected factors to explain users' acceptance towards a new technology:

- The External Variables affect the perceived usefulness, the perceived ease of use, and the attitude towards using a technology.

- $\quad$ The Perceived Usefulness refers to people's perception that the use of a particular technology will improve their ability in doing daily actions or their work performances (Venkatesh \& Davis, 2000).

- The Perceived Ease of Use refers to the required effort to use the system, and then to the people's perception that using a particular technology will be easier (Venkatesh et al., 2003).

- $\quad$ The Attitudes towards Use designates the users' desirability to use a particular technology (Malhotra \& Galletta, 1999).

- $\quad$ The Behavioral Intention to Use is foreseen by the attitude towards use in combination with the perceived usefulness.

- $\quad$ The Actual System Use is foreseen by the behavioral intention.

The TAM model has been expanded and modified by other studies. The most important two were the TAM2 (Venkatesh \& Davis, 2000) and the Unified Theory of Acceptance and Use of Technology (UTAUT) (Venkatesh et al., 2003). Venkatesh and Davis (2000) extended the original TAM proposing the TAM2, including it in social influence processes (subjective norm, voluntarism, and image) and cognitive instrumental processes (job relevance, output quality, result demonstrability, and perceived ease of use). Attitude toward use was considered a weak predictor of behavioral intention or actual use by TAM2. Another extension of the TAM was the Unified Theory of Acceptance and Use of Technology (UTAUT). This model distinguishes factors that determine use behavior (performance expectancy, effort expectancy, social influence, and facilitating conditions) and factors that mediate them (gender, age, experience, and voluntariness) (Venkatesh et al., 2003).

Social influence was not taken into account by the original TAM. Although different studies considered social influence as being a factor in their technology acceptance approaches (Thompson et al., 1991; Moore and Benbasat, 1991), the construct of subjective norm as the main representation of social influence was mostly accepted (Venkatesh et al., 2003). Subjective norm is referred to the perception of a social pressure to engage or 
not to engage in a behavior (Fishbein \& Ajzen, 1975). It is defined as "the degree to which an individual perceives that important others believe he or she should use the new system" (Venkatesh et al., 2003). TAM2 uses subjective norms to explain social influence. It occurs when an individual perceives that an important person has the ability to reward or punish some compliant behaviors, then he/she changes his/her behavior accordingly (Venkatesh \& Davis, 2000).

Ehsaei and Che Hussin, (2012) proposed a model for acceptance of feedbacks in reputation system based on social relations of users that includes homophily, tie strength and source credibility as factors that influence acceptance.

Belkhamza and Wafa (2013) analysed the relationship between perceived usefulness, attitude, and subjective norm in order to assess the differences of behavioral intentions to use e-commerce in the two different countries. They found that uncertainty avoidance plays an important role across culture in the e-commerce adoption.

Ferri et al. (2014) proposed a model to analyse acceptance to use mobile technologies for shopping purposes. They analysed how social influence acts on some indicators related to mobile interaction and experience during use, such as: socio-anagraphic (gender, age, education), motivational (curiosity, image and fashion), functioning (usability, usefulness and mobile convenience), and psychological (cognitive effort, trust, perceived risk and enjoyment), to explain the acceptance process.

Literature showed that social environment and personal interactions have powerful effects on human behavior. Opinions and behaviors of people are influenced by their network (Weimann, 1983). Consumer's purchasing decisions then e-commerce acceptance are always influenced by each other. Starting from this assumption, the paper proposes a model based on social influence that takes into account three fundamental elements of social networks that can influence users: Network Centrality, Homophily and Electronic Word of Mouth to show how these affect consumer behavior and acceptance of e-commerce.

\section{Method}

The study has been carried out by using the deductive method, which enabled us to draw general assumptions derived from theoretical reflection. The deductive approach is in fact a logical process consisting in deriving, from one or more known theories or premises, a conclusion that is logically necessary consequence. "The deductive approach follows the path of logic most closely. The reasoning starts with a theory and leads to a new hypothesis. This hypothesis is put to the test by confronting it with observations that either lead to a confirmation or a rejection of the hypothesis" (Snieder \& Larner, 2009, p. 16).

Thereby, in the first step some assumptions have been formulated. In the second step an analysis of various sources of evidence has been provided to strengthen our assumptions. Finally in the third step, the conceptual model has been built and some variables of social influence have been introduced. In particular different aspects of social influence have been considered for the analysis based on previous researches and theories.

\subsection{Assumptions}

Why people tend to buy some products instead of others with similar characteristics and but cheaper?

When people make a decision and do not know how to behave, just look at what others are doing and act accordingly. This principle is at the basis of the spread of fashions. People tend to behave and dress in a certain way, because they feel that it is more correct.

Other examples are the reviews online, the votes of other users on a product: in this case, the positive testimony of others can be a strong persuasive element for purchase. Generally, people tend to consider more reliable and welcome favorably the opinion of people who know, are more similar to them or are they like nice people. Social influence is able to modify attitudes.

Starting from these examples, the following main assumptions have been made:

- In social networks, opinions of other people in their own social circle have positive impacts in influencing consumer decision to shop online.

In particular, three elements that act in the context of social networks have important positive impacts in influencing consumer acceptance:

- Network Centrality. A user in a social network with high centrality is usually more highly influential than other isolated users.

- Homophily. Users in a social network are most influenced by other similar users with common features (age, gender, interests). 
- Electronic Word of Mouth. Idea, opinions and recommendations propagate very quickly and exponentially in a network promoting products through social relations and encouraging other people to buy online.

These assumptions are next described in detail. The following sections provide the theoretical foundations for the proposed conceptual model.

\section{Social Influence}

Social influence refers to change of a person's behavior after an interaction with other people, organizations and in general with society. It consists of the process by which the individual opinions can be changed by the influence of other individuals (Friedkin, 1998).

It is characterized by three main features: i) conformity, that occurs when an individual expresses a particular opinion in order to meet the expectations of a given other, though s/he does not necessarily hold that belief that the opinion is appropriate; ii) power, that is the ability to force someone to behave in a particular way by controlling his/her outcomes; iii) authority, that is power that is believed to be legitimated by those who are subjected to it (Guzzo et al., 2014).

Webster's dictionary defines influence as "the power or capacity of a person or things in causing an effect in indirect or intangible ways". It could be defined as the combination of all things that may change or have some effects on a person's behavior, thoughts, actions, or feelings. It can be represented by peer pressure, persuasion, marketing, sales, and conformity. This phenomenon in social networks refers to the behavioral change of individuals affected by others in a network. The social environment and personal interactions have powerful effects on human behavior that in fact is always influenced by each other.

In literature three types of reference group influences are identified: Informational Influence, Utilitarian Influence, and Value-Expressive Influence (Park \& Lessig, 1977; Bearden \& Etzel, 1982).

- The Informational Influence acts when individual would like to improve his knowledge and have best and useful information in order to optimize his choices (Kelman, 1961).

- The Utilitarian Influence is based on the compliance process and acts when individual would like to satisfy group's expectation in order to achieve a favorable reaction from it (Kelman, 1961).

- The Value-Expressive Influence is based on the identification process and acts when individual would like to be similar to the group in order to belong to it (Kelman, 1961).

These three types of reference group influences can be applied to online reference groups of social networks and have an impact on consumers' acceptance.

The exponential growth of online social networks such as Facebook, Twitter, MySpace, Flickr, del.icio.us etc. is playing an important role in shaping the user behavior on the web. Fowler and Christakis (2008) introduced the theory of three degrees of influence to explain the great influence that social networks have on people' behavior. According to them people influence friends who in their turn influence their friends, meaning that actions can influence people they have never met. They claim that "everything we do or say tends to ripple through our network, having an impact on our friends (one degree), our friends' friends (two degrees), and even our friends' friends' friends (three degrees). Our influence gradually dissipates and ceases to have a noticeable effect on people beyond the social frontier that lies at three degrees of separation".

Some studies analysed the impact of the social influence on consumer preferences. Domingos and Richardson (2001) modeled markets as social networks of consumers and analysed how to optimize profit by focusing on the most influential consumers. Cosley et al. (2010) proposed a model of how influence propagates through a social network.

Within a social network three main elements act on social influence: i) the Network centrality, ii) the Homophily and iii) the Electronic word of mouth. Some evidences of these influences are provided in the next sections.

\subsection{Network Centrality}

In a social network, members (nodes associated with others nodes) are influenced by others members for various reasons. Social influence is a directional effect from node A to node B. Some nodes can have intrinsically higher influence than others due to network structure. Social Network Analysis is the study of social relations among a set of actors (nodes). The nodes in the network are people and groups while the links show relationships or flows between the nodes. The analysis allows "to determine if a Virtual Social Network is tightly bounded diversified or constricted, to find its density and clustering, and to study how the behaviour of network members is affected by their positions and connections" (Scott, 2000). The importance of a node in the network is measured by its 
centrality. The three most important individual centrality measures are: i) the Degree Centrality, ii) the Betweenness Centrality and iii) the Closeness Centrality.

i) The Degree Centrality refers to the number of direct connections a node has. Persons high in degree centrality can act as opinion leaders within a network. They in fact often play an important role when share information, influencing others or bridging different communities (Chau \& Xu, 2005).

ii) The Betweenness Centrality quantifies the number of times a node acts as a bridge along the shortest path between two other nodes. Persons high in beetweenness centrality often act as communication channels or bridge between two (sub-)networks (Chau \& Xu, 2005). This indicates a dependency of one actor to communicate with other actors then to influence them.

iii) The Closeness Centrality that is the inverse of farness, which in turn, is the sum of distances to all other nodes. Persons high in closeness centrality tend to hear information sooner than others (Cross \& Parker, 2004, p. 157). They are sooner influenced by social pressures, but they also control these pressures by spreading information or not.

A node with high centrality is usually more highly influential than other nodes. According to Katona et al. (2011) demographics and user's position can predict their influential power on their neighbors. Social Network Analysis analyses which members are individuals or peripheral in a network; it identifies bonding and bridging and who has influence in the network.

\subsection{Homophily and Social Similarity}

Homophily can be defined how the tendency of individuals to associate with people similar to themselves. The networks of people are homogeneous respect to some characteristics: sociodemographic, behavioral and intrapersonal. Homophily is at the basis of social ties and it has many implications on people interactions, attitudes and information they receive. It can be divided into cognitive homophily (preferences, attitudes, values) and demographic homophily (race, age) (McPherson et al., 2001).

Homophily is a fundamental characteristic of social networks. In a social network in fact, individuals are connected to each other due to their similar attributes developing social relations. Homophily has important implications on how information flows along the social network (Golub \& Jackson, 2011) and on how this has influence on social behavior. Previous researches have suggested that people who are in the same social circle have similar behaviors and tastes. Similarity among individuals affects trust ad understanding (Ruef et al., 2003) and acceptance of a source information (Bruyn \& Lilien, 2008; Money et al., 1998). Individuals can influence others in accepting advices and ideas through sharing of preferences, tastes and lifestyle (Brown et al., 2007).

The approach based on homophily was followed by Crandall et al., (2008) that used cosine similarity to compute the similarity between two people. They proposed a probabilistic model which samples activities of people based on their history and those of their neighbors, and a background distribution. This concept was stressed also by Matsuo and Yamamoto (2009). They studied user's behavior on e-commerce site and found that users generally trust other users who have similar behavior with them. Other studies analysed the correlation between social similarity and influence. Singla and Richardson (2008) studied the probability of relationships between two users by measuring their similarity. According to them, users with common features (age, gender, zip code, word and queries issued) chat more likely each other, then influence probabilities could be estimated by user's similarity. Homophily is also linked to strong ties. According to McPherson et al. (2001) in fact, strong ties exist among similar individuals and weak ties tend to exist between dissimilar others. Strong ties play a major role in influencing other people through a process of knowledge because they are based on trust and can reduce resistance and uncertainty. Actors who share a strong tie tend to share similar views, offer emotional support and help in times of emergency and are more likely to trust one another (Crona \& Bodin, 2006).

\subsection{The Electronic Word of Mouth}

In social networks very important is the effect of "word of mouth", since ideas, opinions and recommendations propagate very quickly and with an exponential grow. Several studies demonstrated the success of word of mouth for promoting products through social relations encouraging other people to adopt a certain innovation, such as buying a product or watching a movie. This phenomenon is growing in social networks and this assumes an important role in consumer acceptance. Chevalier and Mayzlin (2006) found that word of mouth has a great impact on increase sales thanks to the online book reviews.

In the last years, social network services such as Douban (http://www.douban.com/) and Goodreads (http://www.goodreads.com/), where users rate books, music and movies and share their ratings and reviews with friends or followers, are having a great success. Many companies have recently started to capture data on the 
social interaction between consumers in social networks, with the objective of understanding and leveraging how this interaction can generate social influence. Consumers can modify their opinions about products and/or services according to the social influence process; this process also impacts on knowledge diffusion about products and services. Social network emerges as one of the most authoritative and influential source of knowledge about products and services related to the area of interest of a community. They have the aptitude to generate knowledge sharing among consumers and facilitate the collaboration and exchange of ideas among consumers. (Guzzo et al., 2014). De Bruyn and Gary (2004) call this phenomenon viral marketing; it is a "consumer-to-consumer (or peer-to-peer) communication, as opposed to company-to-consumer communications, to disseminate information about a product or a service, hence leading to its rapid and cost-effective market adoption". Word of mouth or viral marketing involves customers in commercial strategies for recommending commercial products to their friends through the customer social networks. In this context, the problem of the influence maximization that aims to identify individuals to target to have a large cascade of further adoptions, assumes a great relevance. Several studies (Domingos \& Richardson, 2001; Kimura \& Saito, 2006; Chen et al., 2009, 2010), addressed this issue.

\section{E-Commerce Consumer Acceptance Model}

In the previous sections we provided theoretical foundations to design our conceptual model. In table 1, some evidences that emerged from literature are summarized.

Table 1. Summary of evidences from literature review

\begin{tabular}{|c|c|}
\hline & Literature Review \\
\hline \multirow{4}{*}{ NETWORK CENTRALITY } & $\begin{array}{l}\text { In the network a node with high centrality score is usually considered more highly influential } \\
\text { than other nodes (Muruganantham and Meera Gandhi, 2014). }\end{array}$ \\
\hline & $\begin{array}{l}\text { Persons high in degree centrality can act as opinion leaders within a social network influencing } \\
\text { others members (Chau, and } \mathrm{Xu}, 2005) \text {. }\end{array}$ \\
\hline & $\begin{array}{l}\text { Persons high in beetweenness centrality can act as communication channels or bridge between } \\
\text { two sub-networks. This indicates a dependency of one actor to communicate with other actors } \\
\text { then to influence them (Chau and } \mathrm{Xu}, 2005 \text { ). }\end{array}$ \\
\hline & $\begin{array}{l}\text { Persons high in closeness centrality tend to hear information sooner than other. They are sooner } \\
\text { influenced by social pressures, but they also control these pressures by spreading information or } \\
\text { not (Cross and Parker, 2004). }\end{array}$ \\
\hline \multirow{4}{*}{ HOMOPHILY /SIMILARITY } & $\begin{array}{l}\text { Similarity among individuals affects trust ad understanding (Ruef, Aldrich, \& Carter, 2003) and } \\
\text { acceptance of a source information (Bruyn and Lilien, 2008; Money, et al., 1998). }\end{array}$ \\
\hline & $\begin{array}{l}\text { Strong ties typical of similar people play a major role in influencing other people because they } \\
\text { are based on trust (Crona and Bodin, 2006). }\end{array}$ \\
\hline & $\begin{array}{l}\text { Singla and Richardson (2008) analysed the correlation between social similarity and influence. } \\
\text { Users with common features chat more likely each other, then tend to influence each other. }\end{array}$ \\
\hline & $\begin{array}{l}\text { People adopt behaviors exhibited by those they interact with and are similar to them (Friedkin, } \\
\text { 1998). }\end{array}$ \\
\hline \multirow{4}{*}{$\begin{array}{l}\text { ELECTRONIC WORD OF } \\
\text { MOUTH }\end{array}$} & $\begin{array}{l}\text { Chevalier and Mayzlin (2006) found that word of mouth has a great impact on increase sales } \\
\text { thanks to the online reviews. }\end{array}$ \\
\hline & $\begin{array}{l}\text { Consumers can modify their opinions about products and/or services according to the social } \\
\text { influence process (Guzzo et al. 2014). }\end{array}$ \\
\hline & $\begin{array}{l}\text { Word of mouth is a central channel of interpersonal influence in consumer purchase decision } \\
\text { making (Grewal et al. 2003). }\end{array}$ \\
\hline & Word of mouth changes people's opinions, behaviors, feeling and actions (Huang, 2011). \\
\hline
\end{tabular}

Starting from these studies, we used these three elements above analysed: Network Centrality, Homophily, Electronic Word Of Mouth as variables that affect social influence in social networks environment. Figure 1 shows the model that integrates the TAM and TAM 2 by adding some specific variables to explain how user's behavior and acceptance of e-commerce are influenced by other members in social networks. Although TAM2 
has been used to study online shopping environments and takes into account social influence, it does not capture some specific characteristics in the context of social networks. To overcome this lack, we developed the ECA model integrating traditional factors from TAM by adding other variables in the specific context of social networks.

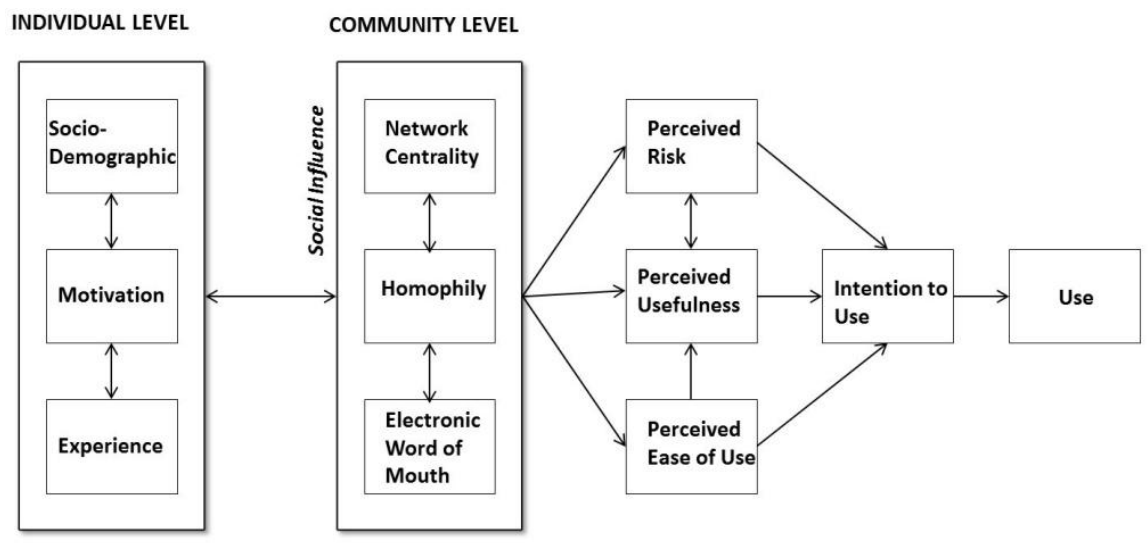

Figure 1. E-commerce consumer acceptance model - ECA

The ECA model represented in figure 1, is based on the idea that e-commerce acceptance depends on social influence within social networks environments. The model takes into account two perspectives that act as variables of input in the process of consumer acceptance, one at individual level that acts on the basis of the different characteristics of the user and one at community level that determines social influence in social networks.

The rectangles within the two blocks: individual level and community level represent variables of input and the other rectangles represent variables of output towards acceptance. The arrows indicate the influence of a variable on the others and their dependences (see figure 1).

Acceptance in terms of "use" depends on the "intention to use" e-commerce, which depends in turn on the variables: "Perceived Usefulness", "Perceived Ease of Use" already introduced by TAM and "Perceived Risk" that influence each other. Our model introduces the "Perceived Risk" that was not taken into account by TAM and TAM2. As we analyse e-commerce acceptance, "Perceived Risk" is a very important variable in affecting consumer acceptance, given the implicit uncertainty of the e-commerce environment also for the use of credit card and possible fraud. In this case, opinions of other people and in particular people of own social circle that experienced similar purchases and who people trust, are very useful in the decision process. These perceptions in fact are affected by social influence (friends, peers, experts, opinions and reviews on social media) that act at community level and in particular three are the variables within social networks environments that according to our model must be taken into account to analyse consumer acceptance. These variables are: Network Centrality" (the most influential person(s) in a social network that has the power to influence other) "Homophily" (the tendency of people to relate whit people with similar tastes, preferences and opinions, then to influence each other) "Electronic Word of Mouth" (the passing of information from person to person on Internet, also by using online reviews, then to influence consumer behavior). These variables can be considered factors of propagation of social influence in the specific context of social networks. The variables at community level act on variables at individual level: "Socio-demographic" (sex, age, employment, qualification, level of education, etc.), "Motivation" (curiosity, image, fashion, etc.), "Experience" (degree of direct knowledge). People, in fact, have different motivations, different approaches with technology and different opinions according to their different ages, social status, level of education, profession, experience, motivations but also in basis at the different degree of social influence received. Then the individual level and the community level are linked among them because they can have reciprocal effects. Also variables within two levels are linked among them because they can influence each other.

All variables identified and their relations have been discussed with seven interdisciplinary experts (engineers, economists, sociologists and psychologists). The aim was to build and verify the theoretical model by using different point of view and to find shared opinions. All experts have been agree in considering the variables introduced in our model as factors that can influence the e-commerce consumer acceptance process. The study 
should be considered as exploratory because it focuses on model building rather than testing. This methodological limitation will be overcome in a second study where the proposed model will be empirically tested using the data collected from a survey with a quantitative approach of Italian consumers. However, this study contributes to a better understanding of consumer acceptance through social media and can help in the successful marketing strategies. Companies can use this model to manage effective strategies for promoting products through social relations within social networks.

\section{Conclusion}

The aim of the paper was to study consumer acceptance of e-commerce from a social network perspective extending the original TAM and TAM 2 by including other variables.

The contribution of the paper to existing knowledge consists in a better understanding of the social influence within social networks environment in affecting e-commerce acceptance. Although different studies considered social influence in technology acceptance models, low attention has been given to how social influence occurs in social networks environments and in relation to e-commerce. Our model introduces some variables that take into account the specific characteristics of the social networks in influencing people decisions.

The model considers two perspectives that act as variables of input in the process of consumer acceptance, one at individual level and one at community level. The variables at individual level are: Socio-demographic, Motivation and Experience that act on the basis of the different characteristics of the user. The variables at community level instead determine social influence in social networks, and are: i) Network Centrality: the activities and preferences of people are influenced by their position in a social network. Persons highly central tend to mainly influence other people in the network; ii) Homophily: two users that have similar preferences tend to influence among them in social networks; iii) Electronic Word of Mouth: users in social networks are influenced by the electronic word of mouth.

These variables at individual level and at community level influence each other's and in turn influence users perception. In particular the variables considered by our model are: Perceived Usefulness and Perceived Ease of Use introduced by TAM and Perceived Risk added by our model due to uncertainty related to the specific context of e-commerce. The sum of the previous variables acts on intention of use of the users and then on the use and acceptance of the technology for e-commerce.

The identified variables have been discussed with seven interdisciplinary experts (engineers, economists, sociologists and psychologists) in order to evaluate the theoretical model by using different point of view and to find shared opinions. However, the limitation of this study is that the model is conceptual and it was not empirically tested but it is based on a literature review. The study should be considered as exploratory because it focuses on model building rather than testing. We used a limited number of experts that verified the model in a qualitative way. This did not enable a generalization of the results, but it has enabled us to build the model. This limitation will be overcome by further studies where the proposed model will be empirically tested on the creative enterprises community available at www.shapes.cnr.it (Ferri et al., 2013; Grifoni et al., 2014; Ferri et al., 2014). For the model validation could be used a social network analysis and/or a survey by using a quantitative approach. The structural equation modeling technique could be used to evaluate the causal model and the confirmatory factor analysis could be performed to examine the reliability and validity of the measurement model. However the ECA model introduced in this study have some practical implications. Online shopping decisions are influenced by other members of the social networks that had similar experiences, by messages in online discussion and reviews of other users. The model can be useful to companies to develop their marketing strategies, because it gives a view on variables to consider within social networks that influence people in their decision process to buy online. This study in fact, shows that it is very important to analyse network structure to increase the flow of information regarding a new product and new ways to buy, for increasing its acceptance by consumers.

\section{References}

Ajzen, I. (1985). From intentions to actions: A theory of planned behavior. In Kuhi J., \& Beckmann J. (Eds.), Actionócontrol: From cognition to behavior (pp. 11-39). Heidelberg: Springer. http://dx.doi.org/10.1007/978-3-642-69746-3_2

Ajzen, I. (1991). The theory of planned behavior. Organizational Behavior and Human Decision Processes, 50(2), 179-211. http://dx.doi.org/10.1016/0749-5978(91)90020-T

Ajzen, I., \& Fishbein, M. (1980). Understanding Attitudes and Predicting Social Behavior. Englewood Cliffs: Prentice-Hall. 
Bearden, W. O., \& Etzel, M. J. (1982). Reference group influence on product and brand purchase decisions. Journal of Consumer Research, 9, 183-194. http://dx.doi.org/10.1086/208911

Belkhamza, Z., \& Wafa, S. A. (2013). The Role of Uncertainty Avoidance on E-Commerce Acceptance across Cultures. International Business Research, 6(3).

Brown, J., Broderick, A. J., \& Lee, N. (2007). Word of mouth communication within online communities: conceptualizing the online Social network. Journal of Interactive Marketing, 21(3). http://dx.doi.org/10.1002/dir.20082

Bruyn, A. D., \& Lilien, G. L. (2008). A multi-stage model of word of mouth influence through viral marketing. Intern. J. of Research in Marketing, 25, 151-163.

Chau, M., \& Xu, J. (2005). Mining communities and their relationships in blogs: A study of online hate groups. International Journal of Human-Computer Studies, 65, 57-70.

Chen, W., Wang, C., \& Wang, Y. (2010). Scalable influence maximization for prevalent viral marketing in large-scale social networks. In KDD '10, Washington

Chen, W., Wang, Y., \& Yang, S. (2009). Efficient influence maximization in social networks. In KDD '09.

Chevalier, J. A., \& Mayzlin, D. (2006). The effect of word of mouth on sales: Online book reviews. Journal of Marketing Research, 43(3), 345-354. http://dx.doi.org/10.1509/jmkr.43.3.345

Cosley, D., Huttenlocher, D. P., Kleinberg, J. M., Lan, X., \& Suri, S. (2010). Sequential influence models in social networks. In 4th International Conference on Weblogs and Social Media.

Crandall, D., Cosley, D., Huttenlocher, D., Kleinberg, J., \& Suri, S. (2008). Feedback effects between similarity and social influence in online communities. In KDD'08, 160-168.

Crona, B., \& Bodin, O. (2006). What you know is who you know? Communication patterns among resource users as a prerequisite for comanagement. Ecology and Society, 11(2), 7-29.

Cross, R., \& Parker, A. (2004). The hidden power of social networks. Boston: Harvard Business School Press.

Davis, F. D. (1989). Perceived usefulness, perceived ease of use, and user acceptance of information technology. MIS Quarterly, 13(3), 319-339. http://dx.doi.org/10.2307/249008

De Bruyn, A., \& Gary, L. L. (2004). A Multi-Stage Model of Word of Mouth Through Electronic Referrals. eBusiness Research Center Working Paper.

Domingos, P., \& Richardson, M. (2001). Mining the network value of customers. Proceedings of the 7th ACM SIGKDD International Conference on Knowledge Discovery and Data Mining. http://dx.doi.org/10.1145/502512.502525

Ehsaei, F. G., \& Che Hussin, A. R. (2012). Acceptance of Feedbacks in Reputation Systems: The Role of Online Social Interactions. Information Management and Business Review, 4(7), 391-401.

Ferri F., Grifoni P., \& Guzzo T. (2013). Factors Determining Mobile Shopping. A Theoretical Model of Mobile Commerce Acceptance. International Journal of Information Processing and Management (IJIPM), 4(7), 89-101.

Ferri, F., Grifoni, P., \& Guzzo, T. (2008). Social Aspects of Mobile Technologies on the Web Tourism Trend. Handbook of research on mobile business: technical, methodological and social perspectives. In Bhuvan Unhelkar (Ed.), IGI Global (pp. 293-303). http://dx.doi.org/10.4018/978-1-60566-156-8.ch027

Ferri, F., Grifoni, P., Caschera, M. C., D’Andrea, A., D’Ulizia, A., \& Guzzo, T. (2014). An Ecosystemic Environment for Knowledge and Services Sharing on Creative Enterprises. Proceeding of the International Conference on Management of computational and collective IntElligence in Digital EcoSystems (MEDES'14, pp. 27-33), 15-17 September 2014, Qassim in Buraydah, Saudi Arabia. http://dx.doi.org/10.1145/2668260.2668308

Ferri, F., Grifoni, P., Caschera, M. C., D’Ulizia, A., \& Praticò, C. (2013). KRC: KnowInG crowdsourcing platform supporting creativity and innovation. AISS: Advances in Information Sciences and Service Sciences, 5(16), 1-15.

Fishbein, M., \& Ajzen, I. (1975). Belief, attitude, intention, and behavior: An introduction to theory and research. Reading, MA: Addison-Wesley.

Fowler, J. H., \& Christakis, N. A. (2008). The Dynamic Spread of Happiness in a Large Social Network: 
Longitudinal Analysis Over 20 Years in the Framingham Heart Study. British Medical Journal, 337, a2338. http://dx.doi.org/10.1136/bmj.a2338

Friedkin, N. (1998). A structural theory of social influence. Cambridge, UK: Cambridge University Press. http://dx.doi.org/10.1017/CBO9780511527524

Golub, B., \& Jackson, M. O. (2011). How Homophily Affects the Speed of Learning and Best-Response Dynamics. The Quarterly Journal of Economics, 127(3), 1287-1338. http://dx.doi.org/10.1093/qje/qjs021

Grewal, R., Cline, T. W., \& Davies, A. (2003). Early entrantant advantage, word-of-mouth communication, brand similarity, and the consumer decision-making process. Journal of Consumer Psychology, 13(3), 187-197. http://dx.doi.org/10.1207/S15327663JCP1303_01

Grifoni, P., Ferri, F., D’Andrea, A., Guzzo, T., \& Praticò, C. (2014). SoN-KInG: a Digital Eco-System for Innovation in Professional and Business domains. Journal of Systems and Information Technology, 16(1), 77-92. http://dx.doi.org/10.1108/JSIT-09-2013-0044

Guzzo, T., D'Andrea, A., Ferri, F., \& Grifoni, P. (2012). Evolution of Marketing Strategies: from Internet Marketing to M-Marketing. OTM 2012 Workshops Proceedings, 10-14 September 2012, Rome. Lecture Notes in Computer Science, 7567, 627-636. http://dx.doi.org/10.1007/978-3-642-33618-8_82

Guzzo, T., Ferri, F., \& Grifoni, P. (2014). Social Influence Analysis. Encyclopedia on Social Network Analysis and Mining. In Reda Alhajj and Jon Rokne (Eds.), Springer Verlag, 1800-1807. http://dx.doi.org/10.1007/978-1-4614-6170-8_186

Huang, J., Boh, W. F., \& Goh, K. H. (2011). From A Social Influence Perspective: The Impact of Social Media on Movie Sales. Proceedings PACIS 2011.

Katona, Z., Zubcsek, P. P., \& Sarvary, M. (2011). Network Effects and Personal Influences: The Diffusion of an Online Social Network. Journal of Marketing Research, 48(3), 425-443. http://dx.doi.org/10.1509/jmkr.48.3.425

Kelman, H. C. (1961). Processes of opinion change. Public Opinions Quarterly, 25, 57-78. http://dx.doi.org/10.1086/266996

Kimura, M., \& Saito, K. (2006). Tractable models for information diffusion in social networks. Proceedings of the 10th European Conference on Principles and Practice of Knowledge Discovery in Databases, pp. 259-271. http://dx.doi.org/10.1007/11871637_27

Malhotra, Y., \& Galletta, D. F. (1999). Extending the Technology Acceptance Model to Account for Social Influence: Theoretical Bases and Empirical Validation. Proceedings of the Thirty-Second Annual Hawaii International Conference on System Sciences, vol. 1. IEEE, Los Alamitos. http://dx.doi.org/10.1109/HICSS.1999.772658

Matsuo, Y., \& Yamamoto, H. (2009). Community gravity: measuring bidirectional effects by trust and rating on online social networks. Proceedings of the 18th international conference on World wide web ACM New York, NY, USA, pp. 751-760. http://dx.doi.org/10.1145/1526709.1526810

McPherson, M., Smith-Lovin, L., \& Cook, J. M. (2001). Birds of a Feather: Homophily in Social Networks. Annu. Rev. Sociol., 27, 415-444. http://dx.doi.org/10.1146/annurev.soc.27.1.415

Money, R. B., Gilly, M. C., \& Graham, J. L. (1998). Explorations of National Culture and Word-of Mouth Referral Behavior in the Purchase of Industrial Services in the United States and Japan. Journal of Marketing, 62, 76-87. http://dx.doi.org/10.2307/1252288

Moore, G. C., \& Benbasat, I. (1991). Development of an Instrument to Measure the Perceptions of Adopting an Information Technology Innovation. Information Systems Research, 2(3), 192-222. http://dx.doi.org/10.1287/isre.2.3.192

Muruganantham, A., \& Meera, G. G. (2014). Identification of Potential Influencers In Facebook Using Network Graph Metrics. Proceedings of 6 th SARC-IRF International Conference, 06th July-2014, New Delhi, India.

Nielsen. (2012). Nielsen: Global Consumers' Trust In 'Earned' Advertising Grows In Importance. Retrieved from http://www.nielsen.com/us/en/press-room/2012/nielsen-global-consumers-trust-in-earned-advertising-grows .html

Park, W., \& Lessig, V. P. (1977). Students and housewives: Differences in susceptibility to reference group influence. Journal of Consumer Research, 4, 102-110. http://dx.doi.org/10.1086/208685 
Ruef, M., Aldrich, H. E., \& Carter, N. M. (2003). The Structure of Founding Teams: Homophily, Strong Ties and Isolation Among U.S. Entrepreneurs. American Sociological Review, 68, 195-222. http://dx.doi.org/10.2307/1519766

Scott, J. (2000). Social Network Analysis: A handbook (2nd ed.). London: Sage.

Singla, P., \& Richardson, M. (2008). Yes, there is a correlation: - from social networks to personal behavior on the web. In WWW'08, pp. 655- 664. http://dx.doi.org/10.1145/1367497.1367586

Snieder, R., \& Larner, K. (2009). The Art of Being a Scientist: A Guide for Graduate Students and their Mentors. Cambridge University Press. http://dx.doi.org/10.1017/CBO9780511816543

Thompson, R. L., Higgins, C. A., \& Howell, J. M. (1991). Personal computing: toward a conceptual model of utilization. MIS Quarterly, 15(1), 125-143. http://dx.doi.org/10.2307/249443

Venkatesh, V., \& Davis, F. D. (2000). A theoretical extension of the technology acceptance model: four longitudinal field studies. Management Science, 46(2), 186-204. http://dx.doi.org/10.1287/mnsc.46.2.186.11926

Venkatesh, V., Morris, M. G., Davis, G. B., \& Davis, F. D. (2003). User acceptance of information technology: toward a unified view. MIS Quarterly, 27(3), 425-478.

Weimann, G. (1983). On the strength of weak conversational ties. Social Networks, 5, 245-267.

\section{Copyrights}

Copyright for this article is retained by the author(s), with first publication rights granted to the journal.

This is an open-access article distributed under the terms and conditions of the Creative Commons Attribution license (http://creativecommons.org/licenses/by/3.0/). 